\title{
REPENSANDO O DIREITO AUTORAL: O COMPARTILHAMENTO DE ARQUIVOS ONLINE COMO DIREITO DE ACESSO À CULTURA
}

Rethinking copyright: the sharing online files as a right of access to culture

\author{
Horácio Wanderlei Rodrigues \\ Amanda Muniz Oliveira \\ Universidade Federal de Santa Catarina -UFSC Florianópolis - Santa Catarina- Brasil
}

Ricardo Rovilson da Silva

\begin{abstract}
RESUMO: O compartilhamento de arquivos online, de forma gratuita e ilimitada, é, por vezes, cerceado em razão das legislações referentes aos Direitos do Autor. Uma vez que esta prática é utilizada - sobretudo - para disseminação cultural, indaga-se se tal compartilhamento não seria uma manifestação do Direito de Acesso à Cultura. Para tanto, analisar-se-á o conceito de cultura, bem como as legislações que a definem como direito humano e lhe garantem acesso; em contrapartida, procurar-seá demonstrar que o compartilhamento gratuito de arquivos não gera prejuízo ao Autor da obra, podendo, inclusive, Ihe trazer benefícios.
\end{abstract}

Palavras-chave: Compartilhamento de arquivos. Arquivos online. Acesso à cultura. DireitoAutoral.

ABSTRACT:The free and unlimited online file sharing is sometimes curtailed because of the laws related to copyrights. Since this practice is used - above all - for cultural dissemination, it is important to ask if such sharing would not be a manifestation of the right of access to culture. That said, the concept of culture will be analyzed, as well as the laws that define it as a human right and ensure you access; for that, will be demonstrated that the free file sharing does not generate damage to the Author of the work, and may even bring him benefits.

Key-words: File sharing. Online files.Accesstoculture. Copyright.

\section{INTRODUÇÃO}

A Cultura, em suas mais diversas manifestações está presente no cotidiano social desde tempos remotos. Transmitida inicialmente de forma oral, perpetuandose por gerações, ao longo do tempo foi e é transcrita e manipulada em suas diferentes formas.

Com o advento do capitalismo, todavia, as obras culturais(artes plásticas, literatura, música erudita) foram transformadas em objetos de consumo. O teatro, as artes plásticas, a literatura, a música e o cinema passaram a ser dotados de cunho 
não apenas moral, referente à autoria, mas comercial, passando a ser vistos como propriedade intelectual de um criador. De forma a garantir não apenas a devida menção à autoria, como também direito exclusivo aos possíveis lucros oriundos de uma criação artística, surge o Direito Autoral, que passa a limitar, de formas diversas, a reprodução e circulação das obras.

Dessa forma, é possível perceber a emergência de um conflito: de um lado, a cultura é compreendida como um direito, sendo garantida, pelo Estado, a sua disseminação; de outro, a produção artística, também entendida como cultura, encontra-se tutelada pelo Direito Autoral, que limita seu alcance. Com o advento da internet, os limites impostos pelo Direito Autoral encontram-se seriamente abalados; os usuários a transformam numa verdadeira terra de ninguém, onde as legislações referentes à proteção do direito dos criadores não surtem os efeitos desejados.

Diante desse conflito faz-se necessário verificar até que ponto 0 compartilhamento gratuito de dados pela internet, visando a disseminação cultural, constitui ameaça aos ganhos econômicos do autor em relação à sua obra. A hipótese aqui defendida é que o compartilhamento gratuito online não só é capaz de gerar lucro, como será demonstrado, mas também se constitui em verdadeiro instrumento doDireito de Acesso à Cultura.

Este trabalho, em termos de fontes,se constitui em uma pesquisa de cunho bibliográfico e documental. Inicialmente, buscaesclarecer o conceito de cultura trabalhado, visto que ela pode ter diversas acepções. Em seguida, procura tecer algumas considerações a respeito do Direito Autoral e do Direito à Cultura. Por fim, objetiva demonstrar que o compartilhamento de arquivos online não constitui ameaça econômica aos Direitos do Autor, além de poder ser compreendido como Direito de Acesso à Cultura.

\section{MAS O QUE É CULTURA?}

Para compreender as implicações do compartilhamento de arquivos online como expressão do Direito à Cultura, faz-se necessária uma breve abordagem sobre o que vem a ser cultura. Como bem assevera Santos (2005), a cultura é uma preocupação contemporânea;e essa preocupação, nos dias atuais,faz parte da recorrente busca em entender os muitos caminhos que conduziram os grupos humanos às suas relações presentes e suas perspectivas de futuro. 
Ademais, a cultura exerce papel fundamental no desenvolvimento da humanidade, que se encontra marcado por contatos e conflitos entre modos diferentes de organizar a vida social, de se apropriar dos recursos naturais e transformá-los, bem como de reconhecer a realidade e expressá-la. A esse respeito, Chauí (1995, p. 81) salienta a necessidade de alargar o conceito de cultura, vislumbrando-o no sentido de invenção coletiva de símbolos, valores, ideias e comportamentos, "de modo a afirmar que todos os indivíduos e grupos são seres e sujeitos culturais".

Pode-se compreender a cultura de diversas maneiras. Tem-se o conceito amplo de cultura, conforme propõe Chauí (1995), como sendo o conjunto de significados e valores dos grupos humanos. Nesta primeira concepção, a cultura é definida como um sistema de signos e significados criados pelos grupos sociais, pois, como ressalta Botelho (2001, p.2), ela se produz "através da interação social dos indivíduos, que elaboram seus modos de pensar e sentir, constroem seus valores, manejam suas identidades e diferenças e estabelecem suas rotinas".

Tem-se a cultura como instrumento voltado para o desenvolvimento político e social do indivíduo, sendo que o campo da cultura se confunde com o campo social. Observa-se que nessa concepção, é ressaltado o papel da cultura como um fator primordial de desenvolvimento social. Nesse sentido, a UNESCO (2006, p.43) afirma que:

[...] a relação entre cultura e desenvolvimento vai bem mais além dos aspectos econômicos; o que significa um desafio ainda maior para a medição e monitoramento do impacto das ações concebidas. $O$ Brasil é um campo fértil para o desenvolvimento de projetos em que a cultura tenha um papel central, devido a sua notável diversidade criativa.

Já para Santos (2005), o conceito de cultura é algo extremamente genérico, que tem sempre como ponto de partida um grupo social, seja este um Estado-Nação ou um vilarejo com seus costumes. Santos (2005, p. 21) afirma que:

Por cultura entende-se muita coisa [...]. Cultura está muito associada a estudo, educação, formação escolar. Por vezes se fala de cultura para se referir unicamente às manifestações artísticas, como o teatro a musica a pintura a escultura. Outras vezes, ao se falar na cultura da nossa época ela é quase que identificada com os meios de comunicação em massa, tais como o rádio, o cinema, a televisão. Ou então cultura diz respeito às festas e cerimônias tradicionais, às lendas e crenças de um povo, ou ao seu modo de vestir, à sua comida, a seu idioma. A lista pode ser ampliada. 
Visto que o termo cultura comporta diversas acepções, para efeitos deste trabalho ela será compreendida como o conjunto de obras intelectuais passível de exploração econômica, conforme as normas do Direito Autoral. Isto porque, de acordo com Adorno e Hockheimer (1985), existe uma forte relação entre cultura e lucro, vez que a primeira passa a ser vista como bem de consumo.

Para os referidos autores (1985), o capitalismo se apropriou da cultura burguesa elitizada (artes plásticas, literatura, música erudita) e a transformou em objeto de consumo, modificando-as e adaptando-as para os indivíduos consumidores. A cultura passa, então, a deter caráter econômico - mera mercadoria, para ser vendida e consumida. Segundo Adorno e Hockheimer (1985, p.57), a cultura torna-se industrializada e obedece a certos padrões de produção. Tais padrões "teriam resultado originariamente das necessidades dos consumidores".

Isso posto, verifica-se que a cultura possui essa característica comercial. Todavia, ao se pensar a cultura no atual contexto mundial, em que a sociedade está interligada e a informação circula em altíssima velocidade, vislumbra-se a existência de um intercâmbio cultural, em todos os sentidos, por meio da internet.

Tal fato ocorre porque, com o advento da internet, o acesso simultâneo às mais diversificadas informações, torna-se completamente viável: é fácil, rápido e confortável, pois é possível assistir o que há de melhor no cinema francês ou mesmo ler as notícias mais importantes da Rússia, sem abandonar o conforto do sofá da sala. Nesse sentido, a internet, passa a ter relevância na distribuição de informação em escala mundial, tornando-se disseminadora cultural em todo o planeta.

Entretanto, importante ressaltar que esse livre acesso à informação é marcado por divergências. Ocorre que, sem grandes dificuldades, os usuários encontram na internet a disponibilização gratuita de músicas, filmes, séries, jogos, etc., o que faz com que seus criadores ou detentores de Direitos Autorais se sintam economicamente lesados. Afinal, para que gastar dinheiro em algo possível de se encontrar, gratuitamente, no conforto do lar, via internet?

Assim, tem-se a ideia da internet como uma grande rede que se destina à transmissão gratuita de informação. Para Paesani (2007, p. 72):

As leis que norteiam o comércio são estranhas à cultura anárquica da internet. Lá a ética é a disseminação do conhecimento e qualquer coisa que se encontra no espaço cibernético é nosso. Estabeleceuse o socialismo digital para o qual a Lei não tem defesas. 
Visando amenizar os efeitos econômicos que o compartilhamento gratuito de arquivos via internet origina, os criadores ou detentores de direitos desses arquivos recorrem ao Direito Autoral. Dessa forma, tem-se um verdadeiro conflito de direitos: um lado o Direito Autoral, visando proteger a criação intelectual e os lucros dela oriundos e, de outro, o Direito à Cultura, visando proteger o livre acesso as diversas formas de manifestações artísticas.

\section{CONSIDERAÇÕES SOBRE O DIREITO AUTORAL}

Quando se pensa em compartilhamento gratuito de arquivos online, os direitos pertencentes ao criador da obra são imediatamente invocados. Os Direitos Autorais, compreendidos por Bittar (2005) como ramo do Direito Privado regulador das relações jurídicas oriundas da criação e do uso econômico das obras intelectuais, possuem uma característica dupla. É que para Branco (2007), o Direito Autoralrefere-se tanto aos direitos da personalidade ${ }^{1}$, carecendo, portanto, de avaliação pecuniária, como a um aspecto econômico, que encontra fundamento nos direitos patrimoniais.

Conforme a Constituição Federal (1988), artigo 5ㅇ, inciso XXII², o direito de propriedade é garantido. Assim, de acordo com Barbosa (2003), o Direito Autoral é um tipo especial de propriedade; é propriedade intelectual. Para o referido autor (2003, p. 1), a propriedade intelectual é a soma dos direitos relativos às:

[...] obras literárias, artísticas e científicas, às interpretações dos artistas intérpretes e às execuções dos artistas executantes, aos fonogramas e às emissões de radiodifusão, às invenções em todos os domínios da atividade humana, às descobertas científicas, aos desenhos e modelos industriais, às marcas industriais, comerciais, à proteção contra a concorrência desleal e todos os outros direitos inerentes à atividade intelectual nos domínios industrial, científico, literário e artístico.

Observe-se, portanto, que se pode falar em duas grandes categorias da propriedade intelectual: uma voltada ao artístico e outra referente ao comércio e à indústria. Conforme Carboni (2003), as obras produzidas no plano técnico tem sua

1 Os direitos da personalidade são aqueles positivados no Código Civil Brasileiro (artigo 11 ao 21). São direitos inerentes a personalidade do indivíduo, possuindo por característica a inalienabilidade e a impossibilidade de se transmiti-los, dentre outras.

2 Constituição Federal, Art. $5 \stackrel{\circ}{\circ}$, inciso XXII - é garantido o direito de propriedade.

Revista do Direitoda UNISC, Santa Cruz do Sul, v.1, n. 45, p. 31-45, jan. - abri. 2015. 
proteção tutelada pela propriedade industrial, enquanto as referentes à estética artística são tuteladas pelo Direito do Autor.

O conjunto de prerrogativas legais que protegem criador e obra, podem ser compreendidos como verdadeiros Direitos Humanos, estando presentes na Declaração Universal dos Direitos Humanos (artigo 27, itens 1 e 2$)^{3}$ e no Pacto Internacional dos Direitos Econômicos, Sociais e Culturais (artigo 15, item 1, letra "a") ${ }^{4}$, além de em diversos outros pactos internacionais ${ }^{5}$.

Em âmbito nacional, gozam de respaldo constitucional, sendo positivados no artigo $5^{\circ}$, inciso XXVII da Constituição Federal ${ }^{6}$, o qual assegura aos autores dos mais variados objetos culturais, o direito de uso, publicação, reprodução e lucro. Também merece menção a proteção conferida pelo Código Penal Brasileiro, que em seus artigos $184^{7}$ e seguintes enumera condutas caracterizadas como crimes contra os Direitos do Autor.

No Brasil, o Direito Autoral é disciplinado pela Lei no 9.610/1998. Uma rápida análise do referido diploma legal aponta que este baseia-se tanto na noção de defesa de autoria, direito da personalidade, quanto na asseguração dos lucros oriundos de produção, direito de propriedade. Os artigos 102 e seguintes corroboram essa assertiva, uma vez que estabelecem uma série de sanções cíveis à condutas consideradas infratoras dos Direitos Autorais. Tais condutas envolvem a reprodução, divulgação ou utilização fraudulenta da obra; edição da obra sem autorização do titular; venda ou ocultação de obra reproduzida com fraude; transmissão ou exposição ao público mediante violação aos direitos de seus titulares; destruição de obstáculos hábeis a impedir ou dificultar a cópia das obras; a não indicação do nome do autor da obra, etc.

3 Declaração Universal de Direitos Humanos. Artigo $27^{\circ}$ - 1. Toda a pessoa tem o direito de tomar parte livremente na vida cultural da comunidade, de fruir as artes e de participar no progresso científico e nos benefícios que deste resultam. 2. Todos têm direito à proteção dos interesses morais e materiais ligados a qualquer produção científica, literária ou artística da sua autoria.

4 Pacto Internacional dos Direitos Econômicos, Sociais e Culturais. Artigo 15 - 1. Os Estados-Parte no presente pacto reconhecem a cada indivíduo o direito de: a) Participar da vida cultural.

5 Bittar (2003) cita como exemplo a Convenção Universal de Genebra (1952) revista em Paris (1971), a Convenção de Washington (1946), Convenção de Estocolmo (1967), etc.

6 Constituição Federal Brasileira. Art. 5ำ, inciso XXVII - aos autores pertence o direito exclusivo de utilização, publicação ou reprodução de suas obras, transmissível aos herdeiros pelo tempo que a lei fixar.

7 Código Penal Brasileiro. Art. 184. Violar direitos de autor e os que the são conexos:Pena detenção, de 3 (três) meses a 1 (um) ano, ou multa. 
Feitas essas considerações gerais a respeito do Direito Autoral, faz-se necessário compreender o que seria o Direito à Cultura e de que forma esse direito estaria ameaçado pelo primeiro.

\section{CONSIDERAÇÕES SOBRE O DIREITO À CULTURA}

Os Direitos Culturais, que estão previstos expressamente na Declaração Universal de Direitos Humanos (1948), encontram-se devidamente normatizados na Constituição Federal de 1988, em seu artigo $215^{8}$, devido à sua relevância como fator de socialização da pessoa humana.

Segundo Machado (2011), os Direitos Culturais são parte integrante dos Direitos Humanos, o que implica dizer que pertencem a uma categoria especial de direitos. Afinal, segundo Rabinovich (2007), os Direitos Humanossão poderes aparados pela comunidade, que geram condutas obrigatórias para os demais, e dos quais se é titular pelo simples fato de ser um membro da espécie humana.

Para Lavorenti (2009), tratam-se de direitos especiais, dotados de características particulares. São universais, pois são aplicáveis a qualquer pessoa, se estendendo à toda cultura humana; são indisponíveis, pois não se pode renunciar à própria dignidade humana; proíbem o retrocesso, vez que uma proteção conquistada jamais poderá ser retirada; inalienáveis, pois não podem ser transferidos; imprescritíveis, vez que não são perdidos com o passar do tempo; invioláveis, porque não podem ser atingidos por agentes públicos ou leis infraconstitucionais e ainda, são dotados de efetividade, pois o Poder Público deve garantir sua aplicabilidade no mundo dos fatos.

Assim, salienta-se que, por ser um Direito Humano e, no Brasil, um Direito Constitucional, o Estado deve não apenas proteger a cultura em suas diversas formas e identidades, mas também fomentá-la, e ainda garantir ao povo o acesso a ela. Para exercer essa proteção e incentivo, o Estado se mune de diversos instrumentos, desde a promulgação de leis, até à criação de um ministério específico, o Ministério da Cultura.

8 Constituição Federal Brasileira. Art. 215. O Estado garantirá a todos o pleno exercício dos direitos culturais e acesso às fontes da cultura nacional, e apoiará e incentivará a valorização e a difusão das manifestações culturais. 
Importante ressaltar, ainda, a criação da Lei no 12.343/2010, que institui o Plano Nacional de Cultura (PNC) e que tem por finalidade o planejamento e implementação de políticas públicas de longo prazo voltadas à proteção e promoção da diversidade cultural brasileira. Dito isso, não há como negar a existência de um Direito à Cultura, em sua forma multifacetada, que engloba desde asmanifestações étnico culturais, até às mais diversas formas de manifestações artísticas.

Apesar disso, é possível dizer que o exercício dos Direitos Culturais é dificultado em função de políticas públicas ineficazes ou inexistentes, bem como limitações decorrentes da legislação dos Direitos Autorais.

Para Wachowicz (2006), faz-se necessário que os Direitos do Autor zelem pelo desenvolvimento e a difusão do conhecimento tecnológico, científico e cultural. Para o referido autor (2006, p. 91):

A Revolução Tecnológica da Informação alça novo nível de exigência
aquém do qual o Estado não pode ficar para ser considerado como
uma forma de democracia: é um nível de exigência com vistas ao
modo pelo qual as pessoas nesse território são tratadas
concretamente para sua inclusão informacional que necessariamente
espelha a sua própria inclusão cultural.

Ademais, Wachowicz (2006) defende que o compartilhamento online e gratuito de arquivos diversos não deve ser visto como infração aos Direitos Autorais, não devendo ser por ele limitado. É que para o autor (2006, p. 91), as regras vigentes que protegem o direito de criação artística foram moldadas anteriormente ao que chama de "revolução da tecnologia da informação e comunicação", devendo portanto observar e se adequar aos novos paradigmas desse novo tipo de sociedade.

Isso posto, cumpre agora demonstrar de que forma o compartilhamento de arquivos online pode ser compreendido como exercício do Direito à Cultura; é o que será feito na próxima seção deste artigo.

\section{O COMPARTILHAMENTO GRATUITO DE ARQUIVOS ONLINE COMO EXERCÍCIO DO DIREITO À CULTURA}

Importante observar que o foco do conflito não é necessariamente o embate entre os Direitos do Autor e os Direitos Sociais de uma coletividade;o conflito versa, na realidade, sobre os direitos de exploração comercial atribuídos ao autor e o 
Direito de Acesso à Cultura. Conforme Rover (2003, p.05), existe um verdadeiro entrave "entre a esfera cultural e a esfera comercial; a cultural primando pela liberdade de acesso e a comercial buscando o controle sobre o acesso e o conteúdo dessa produção cultural, com intuito comercial".

Assim sendo, no intuito de melhor compreender esse entrave, uma análise crítica do compartilhamento de arquivos pela internet faz-se necessária. Antes de mais nada, é preciso esclarecer que o compartilhamento gratuito não pode ser compreendido como pirataria; segundo Souza (2006, p. 123) a pirataria é "a reprodução e distribuição não autorizadas de obras com objetivos econômicos $e$ lucrativos (grifou-se)". O compartilhamento online, por sua vez, não exige contraprestação monetária, sendo que o seu objetivo precípuo não é o de lucrar, mas o de disseminar a obra. Nesse sentido, Cesar (2013) afirma que o compartilhamento de arquivos online não gera circulação financeira. Quem disponibiliza as diversas mídias e obras não busca ganho monetário, mas sim a disseminação de conteúdos de forma livre.

Além disso, a prática do compartilhamento é frequentemente apontada como responsável por significativa perda monetária de seus autores. Como já foi apontado, a finalidade da legislação seria a de também garantir lucro aos criadores de obras artísticas. Nesse quesito, é pertinente indagar até que ponto há uma real e significativa perda econômica, a ponto de ser necessário impedir por completo o compartilhamento desses arquivos.

Como o compartilhamento se dá gratuitamente, o argumento da indústria do entretenimento, de acordo com Vianna (2005), é o de que as pessoas que possuem livre acesso a essas obras não despenderiam capital na aquisição material do produto. É dizer, quem pode fazer o download de um CD em mp3 não compra o álbum do artista, gerando prejuízos a ele; ou quem possui a possibilidade de ter acesso a um filme online, não compra ingressos para o cinema; ou ainda, porque gastar dinheiro em livros quando se pode baixar o arquivo gratuitamente em pdf?

Porém, tal argumento não se sustenta. Vianna (2005) afirma que ao invés de gerar prejuízos, o compartilhamento gratuito pode ser uma ferramenta útil ao autor, de forma a se projetar e a se destacar no mercado em que atua, sendo capaz até mesmo de gerar lucro. 
$\mathrm{Na}$ indústria musical, por exemplo, notícia de 24 de dezembro de 2013, retirada do site Omelete $^{9}$, afirma que a banda Iron Maiden escolheu realizar turnê justamente nos países em que suas músicas foram mais compartilhadas: Brasil, Venezuela, México, Colômbia e Chile lideravam o ranking de compartilhamento online gratuito e foram escolhidos para sediar diversos shows. O resultado: os lucros com venda de ingressos e produtos da banda aumentaram; só o show em São Paulo rendeu $R \$ 2,58$ milhões.

Alguns músicos chegam a defender publicamente o compartilhamento de seu trabalho. Mark Jansen, guitarrista, vocalista e fundador da banda Epica, respondeu em entrevista datada de 28 de fevereiro de $2015^{10}$ que acha a prática ótima. Nas palavras de Jansen ${ }^{11}$ :

Para mim, é uma bênção! O download ilegal faz com que as pessoas escutem nossas músicas e venham aos nossos shows. Para nós, o mais importante é que as pessoas fiquem felizes, e quando elas vêm ao nosso show e compram uma camiseta ou mesmo um álbum, então é ótimo, pois elas estão mostrando que realmente gostaram do nosso trabalho, comprando algo que a banda fez. A era em que as pessoas compravam pilhas e pilhas de CDs já acabou, então é necessário aprender a lidar com isso. Pessoalmente, não me importo nem um pouco com download ilegal, o importante é o apoio à banda e ao trabalho que fazemos.

$\mathrm{Na}$ indústria cinematográfica não é diferente. Tem-se por exemplo o caso do filme campeão de bilheteria, Iron Man 3, orçado em US\$ 200 milhões (duzentos milhões de dólares) e cuja bilheteria alcançou, apenas na semana de seu lançamento US\$ 195 milhões (cento e noventa e cinco milhões de dólares) ${ }^{12}$. Seu faturamento total ultrapassou US\$ 1 bilhão (Um bilhão de dólares) ${ }^{13}$ e ainda assim, até a data de 10 de maio de 2013 (data próxima a de seu lançamento), haviam sido

9 Notícia retirada do site Omelete. Disponível em: $<$ http://omelete.uol.com.br/musica/noticia/ironmaiden-pirataria-atraiu-banda-ao-brasil/>. Acesso em 25 mar. 2015.

10 Notícia retirada do site Metal Revolution. Disponível em: $<$ http://metalrevolution.net/blog/2015/02/28/epica-e-sempre-uma-grande-festa-ir-ao-brasilentrevista-exclusiva-com-mark-jansen/>. Acesso em 25 mar. 2015.

11 Fala retirada da entrevista disponibilizada no site Metal Revolution. Disponível em: $<$ http://metalrevolution.net/blog/2015/02/28/epica-e-sempre-uma-grande-festa-ir-ao-brasilentrevista-exclusiva-com-mark-jansen/>. Acesso em 25 mar. 2015.

12 Notícia retirada do site G1. Disponível em <http://g1.globo.com/poparte/cinema/noticia/2013/04/homem-de-ferro-3-bate-recorde-de-bilheteria-em-estreia-mundial1.html>. Acesso em 25 mar. 2015.

13 Dado retirado do site IGN. Disponível em:<http://www.ign.com/articles/2013/05/17/iron-man-3soars-past-1-billion>. Acesso em 25 mar. 2015. 
feitos 28.803 downloads do filme pela rede de compartilhamento Bit Torrent ${ }^{14}$ - isso sem contar as pessoas que obtiveram acesso ao filme por meio de outras redes.

No que se refere à literatura, a fala de Vianna (2005, p. 248) merece destaque:

A digitalização das obras intelectuais não aboliu a impressão de
livros. As leis, que sempre foram de domínio público, estão
fartamente disponíveis na íntegra na Internet, mas as editoras
jurídicas continuam produzindo e vendendo códigos impressos.
Inúmeras traduções da Bíblia podem ser encontradas na Internet
com facilidade, mas a obra sagrada continua sendo o livro mais
vendido no mundo. A genial literatura de Machado de Assis, em
domínio público pelo passar do tempo, também pode ser encontrada
na Internet, mas várias editoras continuam imprimindo seus
trabalhos, inclusive em edições luxuosas. Se é assim com as obras
de domínio público, do mesmo modo será com as obras tuteladas
pelo 'direito autoral'. Apesar da divulgação destes trabalhos em meio
digital e da sua consequente ausência de escassez, ainda assim
haverá interessados em adquiri-las em edições palpáveis.

Ainda em relação à literatura, é possível citar também casos em que os autores chegam a incentivar o compartilhamento de suas obras. Um exemplo claro é o autor Paulo Coelho, que chegou a manter um blog (Pirate Coelho) ${ }^{15}$ no qual disponibilizava o download de suas obras de forma gratuita. $O$ referido escritor inclusive já discursou a favor da disponibilização gratuita de arquivos e apoiou abertamente o site ThePirateBay, um dos maiores indexadores de conteúdo a ser baixado gratuitamente por internautas, ocasião na qual sua foto estampava a capa do site $^{16}$.

Assim, compreendendo que o compartilhamento de arquivos online não acarreta em prejuízo monetário para o criador da obra, o direito ao lucro referente à propriedade intelectual encontra-se protegido. Ou o seu objetivo não é garantir que o autor receba retorno financeiro pelo que produziu?

No que se refere ao compartilhamento online como acesso à cultura, Rover (2003, p. 116) acredita que se vivencia um conflito:

[...] entre a esfera cultural e a esfera comercial; a cultural primando pela liberdade de acesso e a comercial buscando o controle sobre o

14 Dado obtido ao se ingressar na rede de compartilhamento através do programa conhecido como BitTorrent e iniciar o download do filme em questão no dia 10 de meio de 2013 às 15 horas e 37 minutos

150 site a que se faz referência é <http://paulocoelhoblog.com/2008/02/03/pirate-coelho/>. Acesso em 25 mar. 2015.

16 Notícia retirada do site Techmundo. Disponível em: <http://www.tecmundo.com.br/pirataria/18599paulo-coelho-e-a-nova-capa-do-pirate-bay.htm >. Acesso em 25 mar. 2015. 
acesso e o conteúdo dessa produção cultural, com intuito comercial. Evidentemente, estamos passando por um período de transição, de longo prazo, de um sistema baseado na produção industrial para uma produção cultural, em que o importante não é a propriedade do bem, mas o acesso a ele.

Portanto, o acesso à cultura toma novas formas. Vianna (2005) destaca que o alto valor das obras artísticas faz com que a grande maioria da população deixe de consumi-las. Tal obstáculo poderia ser ultrapassado com o compartilhamento gratuito de arquivos, de forma a garantir a todos os indivíduos acesso livre à cultura. Porém, para Vianna (2005, p.256) os limites jurídicos impostos a prática:

[...] beneficia[m] principalmente a 'indústria cultural', em detrimento da classe hipossuficiente da população, que é obrigada a escolher entre o consumo de bens de subsistência e de bens culturais e acaba optando impreterivelmente por aqueles. Desta forma, aumenta-se o fosso cultural existente entre países desenvolvidos e subdesenvolvidos e, internamente, entre os membros de uma elite econômica e cultural e a massa da população fadada ao trabalho braçal, à miséria e à ignorância.

Uma vez que o acesso à cultura é, conforme apontado, um Direito Humano a ser assegurado pelo Estado, é preciso harmonizá-lo com os pressupostos do Direito Autoral. Se a preocupação maior desse último refere-se aos possíveis prejuízos econômicos que poderiam se originar a partir do compartilhamento online gratuito, foi-se demonstrando também que tal preocupação não encontra razão de ser. Assim sendo, não há que se falar no compartilhamento como ameaça, mas como possibilidade. Nesse sentido, Branco (2007, p.138) afirma:

Um país que tem 6 milhões de crianças vivendo em absoluta pobreza,como é o caso do Brasil, não pode desconsiderar os benefícios da tecnologia nem tampouco encarar os direitos autorais como regra absoluta a ser preservada. Os direitos autorais encontram-se dentro de um contexto muito maior, que envolve regras constitucionais e de caráter internacional que precisam ser respeitadas. Na medida em que a Constituição Federal brasileira impõe a observância da função social da propriedade a todos os gêneros de bem - inclusive os imateriais - é imperioso que a LDA seja lida à luz da Constituição Federal, e não o contrário.

De fato, infere-se que a população não pode ver tolhido o direito de elevar o seu conhecimento e bem estar social. O compartilhamento gratuito via internet permite que o acesso à cultura se efetive de forma prática e rápida, sendo possível presumir que leva obras diversas a pessoas que nunca as acessariam de outra forma. Se o Direito à Cultura é um Direito Humano passível de ser exigido, faz-se necessário que o Direito Autoral auxilie a promoção desse Direito, não que o 
impeça. Em momentos nos quais a lei emerge como espelho distorcido do anseio e da realidade social, faz-se mister refletir sobre os rumos que o Direito deve tomar: manter-se ou adequar-se.

\section{CONSIDERAÇÕES FINAIS}

A cultura, em seus mais diferentes sentidos, deve ser encarada não só como um Direito Constitucional, mas também como um Direito Humano. Levando em consideração que o conjunto de atividades artísticas e intelectuais também deve ser compreendido como cultura, vislumbra-se que o Direito Autoral passa a impor certos limites ao livre compartilhamento de determinas obras artísticas, impedindo assim a efetivação do Direito de Acesso à Cultura.

Conforme demonstrado, a internet permite que diversos usuários compartilhem e disseminem livremente os mais diversos tipos de produções artísticas, de forma gratuita. A suposta preocupação do Direito Autoral, nesse sentido, seria a de que a partir do compartilhamento gratuito, os criadores enfrentariam grande prejuízo econômico, visto que não receberiam retorno financeiro por suas criações.

Todavia, tal argumento não se sustenta. O compartilhamento livre não só é capaz de disseminar o trabalho do artista criador, como também de the expandir mercados e fazer com que seus lucros aumentem. Tanto que muitos artistas não se importam no livre compartilhamento de suas obras, chegando a incentivá-lo e a aproveitá-lo de outras formas.

Verificou-se, portanto, que a proteção autoral sobre as obras artísticas é incompatível com o Direito (Humano) de Acesso à Cultura. Dessa forma, faz-se necessário refletir sobre as atuais normas vigentes relativas ao tema, de forma a adequá-las não somente ao que diz a Constituição Federal, mas ao que está em diplomas normativos relativos aos próprios Direitos Humanos.

\section{REFERÊNCIAS}

ADORNO, Theodor; HORKHEIMER, Max. Dialética do esclarecimento. Rio de Janeiro: Jorge Zahar Ed., 1985. 
BARBOSA, Denis Borges. Uma introdução à propriedade intelectual. Rio de Janeiro: Lumen Juris, 2003.

BITTAR, Carlos Alberto. Direito de Autor. Rio de Janeiro: Forense Universitária, 2005.

BOTELHO, Isaura. Dimensões da cultura e políticas públicas. São Paulo em Perspectiva. Scielo Brasil, v. 15 nํ⒉ São Paulo, 2001.

BRANCO, Sergio. A lei autoral brasileira como elemento de restrição à eficácia do direito humano à educação.Sur. Revista Internacional de Direitos Humanos. São Paulo, v. 4,n. 6, 2007 . Disponível em:

$<$ http://www.scielo.br/scielo.php?script=sci arttext\&pid=S1806-

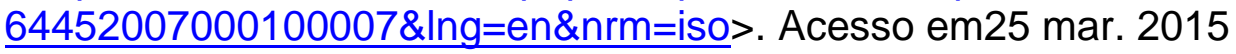

BRASIL. Código Penal. Decreto-Lei oㅡ 2.848, de 7 de dezembro de 1940. Diário Oficial da República Federativa do Brasil, Poder Executivo, Brasília, DF, 7 dez. 1940. Disponível em: <http://www.planalto.gov.br/ccivil 03/decreto-lei/del2848.htm>. Acesso em: 25 mar. 2015.

BRASIL. Constituição da República Federativa do Brasil de 1988. Disponível em: $<$ http://www.planalto.gov.br/ccivil 03/constituicao/constituicaocompilado.htm>.

Acesso em: 25 mar. 2015.

BRASIL. Lei no 9.610, de 19 de fevereiro de 1998. Diário Oficial da RepúblicaFederativa do Brasil, Poder Executivo, Brasília, DF, 18fev. 1998.

Disponível em:<http://www.planalto.gov.br/ccivil 03/leis/l9610.htm>. Acessoem: 25 mar. 2015.

BRASIL. Lei no 12.343, de 2 de dezembro de 2010. Diário Oficial da RepúblicaFederativa do Brasil, Poder Executivo, Brasília, DF, 3 dez. 2010.

Disponível em:<http://www.planalto.gov.br/ccivil 03/ ato20072010/2010/lei/l12343.htm>. Acesso em25 mar. 2015

CARBONI, Guilherme C. O Direito do Autor na multimídia. São

Paulo:QuartierLatin, 2003.

CHAUÍ, Marilena. Cultura política e política cultural. São Paulo: Estudos Avançados, 1995.

CESAR, Daniel Jorge Teixeira. Acultura da cópia:estudo sobre o compartilhamento de arquivos e a prática da pirataria virtual. 2013. 107 f. Dissertação (Mestrado em Sociologia) - Instituto de Ciências Sociais, Universidade de Brasília, Brasília. 2013.

LAVORENTI, Wilson. Violência e discriminação contra a mulher: tratados internacionais de proteção e o direito penal brasileiro. Campinas, São Paulo: Millenium Editora, 2009.

MACHADO, Bernardo Novais da Mata. Direitos Culturais e Políticas para aCultura. In: CALABRE, L. Políticas culturais: teoria e práxis. São Paulo: Itaú Cultural; Rio de Janeiro: Fundação Casa de Rui Barbosa, 2011. Disponível em: 
$<$ http://d3nv1jy4u7zmsc.cloudfront.net/wp-content/uploads/2013/04/PoliticaCulturais-Teoria-e-Praxis.pdf>Acesso em25 mar. 2015

ONU. Declaração Universal dos Direitos Humanos.1948 Disponível em: $<$ http://www.onu-brasil.org.br/documentos direitoshumanos.php $>$ Acesso em 25 mar. 2015

ONU.Pacto Internacional dos Direitos Econômicos, Sociais e Culturais. 1966. Disponível em: <http://www.planalto.gov.br/ccivil 03/decreto/1990-1994/D0591.htm> Acesso em25 mar. 2015

PAESANI, Liliana Minardi. Direito de Informática: Comercialização eDesenvolvimento Internacional do software. 6ª ed. São Paulo: Atlas,2007.

RABINOVICH-BERKMAN, Ricardo David. Derechos Humanos:uma introducción a su naturaleza y a su historia. Buenos Aires: Quorum, 2007.

ROVER, Aires José. Os paradoxos da proteção à propriedade intelectual. In: KAMINSKI, Omar (org). Internet legal: o direito na tecnologia da informação. Curitiba: Juruá. 2003.

SANTOS, José Luiz dos. O que é cultura. São Paulo: Brasiliense., 2005.,

SOUZA, Allan Rocha de. A função social dos Direitos Autorais: uma interpretação civil-constitucional dos limites de proteção jurídica. Campos dos Goytacazes:

Faculdade de Direito de Campos, 2006.

UNESCO.Desigualdade / Políticas culturais. 2006. Disponível em:<http://www.unesco.org.br/Brasil>. Acesso em25 mar. 2015

VIANNA, Túlio Lima. A ideologia da Propriedade Intelectual: a inconstitucionalidade da tutela penal dos direitos patrimoniais do autor. Revista Ajuris, Porto Alegre, v. 99, 2005. Disponível em: <http://livepublish.iob.com.br/ntzajuris//pext.dll/Infobase/19cb5/19d0f/1a549?f=templa tes\&fn=document-frame.htm\&2.0 - JD AJURIS99PG243>. Acesso em 25 mar. 2015.

WACHOWICZ, Marcos. A Revisão da Lei Brasileira de Direitos Autorais. In: WACHOWICZ, Marcos.; SANTOS, Manoel J. Pereira dos (org). Estudos de Direito de Autor: A revisão da lei de Direitos Autorais. Florianópolis: Fundação Boiteux, 2010. 